\title{
Erratum to: How does a firm's management of greenhouse gas emissions influence its economic performance? Analyzing effects through demand and productivity in Japanese manufacturing firms
}

\section{Kimitaka Nishitani $\cdot$ Shinji Kaneko • \\ Satoru Komatsu $\cdot$ Hidemichi Fujii}

Published online: 5 February 2015

(c) Springer Science+Business Media New York 2015

\section{Erratum to: J Prod Anal (2014) 42:355-366}

DOI 10.1007/s11123-014-0388-9

As the reference Nishitani et al. (2011) was not listed correctly in the original publication of the article, it is not referred in CrossRef. The corrected reference is published with this erratum.

\section{Reference}

Nishitani K, Kaneko S, Fujii H, Komatsu S (2011) Effects of the reduction of pollution emissions on the economic performance of firms: an empirical analysis focusing on demand and productivity. J Clean Prod 19(17-18):1956-1964

The online version of the original article can be found under doi:10. 1007/s11123-014-0388-9.

K. Nishitani $(\square)$

Research Institute for Economics and Business Administration, Kobe University, 2-1 Rokkodai, Nada, Kobe 657-8501, Japan

e-mail: kimitakan@ rieb.kobe-u.ac.jp

S. Kaneko

Graduate School for International Development and

Cooperation, Hiroshima University, 1-5-1 Kagamiyama,

Higashi-Hiroshima 739-8529, Japan

\section{S. Komatsu}

School of Global Humanities and Social Science, Nagasaki

University, 1-14 Bunkyo-machi, Nagasaki 852-8521, Japan

H. Fujii

Graduate School of Fisheries Science and Environmental

Studies, Nagasaki University, 1-14 Bunkyo-machi,

Nagasaki 852-8521, Japan 